\title{
Nutrient requirements in Hanwoo cows with artificial insemination: effects on blood metabolites and embryo recovery rate
}

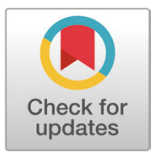

Received: Mar 2, 2020

Revised: Apr 23, 2020

Accepted: May 14, 2020

*Corresponding author

Sang-Rae Cho

Hanwoo Research Institute, NIAS,

RDA, Pyeongchang 25340, Korea.

Tel: +82-33-330-0625

E-mail: davidcho5020@gmail.com

Copyright $@ 2020$ Korean Society of Animal Sciences and Technology.

This is an Open Access article distributed under the terms of the

Creative Commons Attribution

Non-Commercial License (http://

creativecommons.org/licenses/by-

$\mathrm{nc} / 4.0 /$ ) which permits unrestricted

non-commercial use, distribution, and

reproduction in any medium, provided

the original work is properly cited.

ORCID

Sung-Sik Kang

https://orcid.org/0000-0002-9453-5377

Ui-Hyung Kim

https://orcid.org/0000-0002-2197-5080

Man-Hye Han

https://orcid.org/0000-0002-8104-4587

Sang-Rae Cho

https://orcid.org/0000-0003-0209-6248

Competing interests

No potential conflict of interest relevant

to this article was reported.

Funding sources

This study was supported by 2019

RDA Fellowship Program of Hanwoo

Research Institute, Rural Development

Administration, Korea.

Acknowledgements

Not applicable.

\author{
Sung-Sik Kang, Ui-Hyung Kim, Man-Hye Han and Sang-Rae Cho*
}

Hanwoo Research Institute, National Institute Animal Science (NIAS), Rural Development Administration (RDA), Pyeongchang 25340, Korea

\section{Abstract}

Here, we investigated the effects of different nutrient requirements (NR) on blood metabolites, transferable embryo number after multiple superovulations with artificial insemination (Al), body condition score (BCS), and estrus cycle in Hanwoo cow. Nineteen Hanwoo cows were randomly divided into three groups $(80 \%, 100 \%$, and $120 \% \mathrm{NR}$, containing 6,8 , and 5 individuals, respectively) and fed based on the NR. In experiment 1 , glucose, total cholesterol, triglyceride, blood urea nitrogen (BUN), aspartate aminotransferase (AST), alanine aminotransferase (ALT), non-esterified fatty acids (NEFA), albumin (ALB), and total protein (TP) were analyzed. In experiment 2 , total number of recovered embryos and transferable embryos was examined after embryo recovery and multiple superovulations with $\mathrm{Al}$. In experiment 3 , body weight, BCS, and estrus cycle were examined. In experiment 1 , total cholesterol was significantly different among the $80 \%, 100 \%$, and $120 \%$ NR groups $(126.5 \pm 3.3,152.6 \pm 2.4$, and $177.4 \pm 1.8 \mathrm{mg} / \mathrm{dL}$, respectively, $p<0.05$ ). The triglyceride and BUN levels in the $120 \%$ NR group were significantly higher than those in the $80 \%$ and $100 \%$ groups $(p<0.05)$. The NEFA levels were significantly different among the $80 \%, 100 \%$, and $120 \%$ NR groups (440.5 $\pm 18.2,318.5 \pm 23.1$, and $195.1 \pm 8.5$ 4Eq/L, respectively, $p<0.05$ ). The AST and TP levels in the $80 \%$ NR group were significantly lower than those in the $100 \%$ and $120 \%$ NR groups $(p<0.05)$. In experiment 2 , the $120 \%$ NR group showed a higher percentage of transferable embryos than the $80 \%$ and $100 \%$ groups $(p<0.01)$. The mean body weight and BCS among the $80 \%, 100 \%$, and $120 \%$ NR groups were significantly different $(p<0.05)$. The estrus cycle in the $80 \%$ NR group was delayed compared with the $100 \%$ and $120 \%$ NR groups $(20.8 \pm 0.2$ and $21.2 \pm 0.5$ days, respectively). In conclusion, the blood metabolic tests proved that Hanwoo cows with $120 \%$ NR can produce a large number of transferable embryos. Thus, $120 \%$ NR is the appropriate feeding level for this type of cows as it results in the production of a large number of transferable embryos by multiple superovulations with Al.

Keywords: Blood metabolite, Embryo quality, Nutrient requirements, Hanwoo cow 
Availability of data and material Upon reasonable request, the datasets of this study can be available from the corresponding author.

Authors' contributions Conceptualization: Kang SS, Han MH, Cho SR. Data curation: Kang SS. Formal analysis: Kang SS. Methodology: Kang SS, Kim UH. Software: Kang SS.

Validation: Kang SS, Cho SR. Investigation: Kang SS, Cho SR.

Writing - original draft: Kang SS.

Writing - review \& editing: Kang SS.

Ethics approval and consent to participate The animal study design was approved by the IACUC review board (Approval Number: NIAS20191557)

\section{INTRODUCTION}

The reproductive efficiency of dairy and beef cows are important factors influencing the production of milk and meat. In cattle, it is well known that a negative energy balance (NEB) has detrimental effects on reproductive efficiency, such as delaying the estrus cycle [1], reducing the embryo quality [2], and reducing pregnancy rate after insemination [3]. Body condition score (BCS) is used to determine the amount of metabolized energy in the fat and muscle of a live animal [4]. Postpartum cows with NEB and low BCS had abnormal estrus cycles until a normal BCS was restored [5]. The in vivo embryo quality after multiple superovulations, artificial insemination (AI), and embryo recovery depends on the BCS of the donor cow [6]. The nutrient requirements (NR) affect nutrition intake, blood metabolites, ovarian function, the estrus cycle, and fertility [7]. Blood metabolites change with the feeding status, and their levels are used as criteria to evaluate cows' nutritional status [8]. Glucose is mainly metabolized via the glycolytic pathway [9] and used as an energy source for the maturation of oocytes and expansion of the surrounding cumulus cells in vitro [10]. Total cholesterol plays an important role in steroidogenesis regulation in the ovary [11].

Triglycerides are a major lipid in bovine oocytes; for instance, lipolytic activity increases in bovine oocytes during maturation, and the oocytes utilize triglycerides to generate adenosine triphosphate (ATP) [9]. Dairy cows with NEB during ketosis and post parturition had low triglyceride levels. In cows with $\mathrm{NEB}$, stored triglycerides in the adipose tissue are degraded to restore the energy balance [12]. Excess lipids in circulation accumulate as triglycerides in the liver. Alanine aminotransferase (ALT) and aspartate aminotransferase (AST) concentrations in the plasma can be used as liver injury indicators for stored triglycerides in the liver [13].

Elevated plasma urea nitrogen concentrations are caused by high dietary crude protein feeding, and it is associated with decreased fertility in dairy cows [14]. Fertilized oocytes in cows fed high and moderate levels of protein had similar morphological blastocyst developments. However, cows in the moderate feeding group showed a relatively high pregnancy rate after embryo transfer [14]. Different plasma urea nitrogen concentrations affect oocyte competence and embryo developmental rate in vitro [15]. A normal serum albumin concentration in donor cows can be used to predict the in vitro developmental competence of oocytes [16].

It is well known that non-esterified fatty acids (NEFA) is an indicator of cow NEB. Post parturition cows have been shown to have higher NEFA concentrations, produce less milk [17], and have lower fertility [18]. Elevated NEFA concentrations have negative effects on cow granulosa cell viability and cell growth [19], and induce apoptosis in human granulosa cells [20]. However, the nutritional status and effects of changes in blood metabolites, BCS, estrus cycle, and embryo quality have not been thoroughly investigated in Hanwoo cows.

To obtain high quality embryos from elite cows, multiple steps of ovulation, including hormone treatment, AI, and embryo recovery, should be adapted in fields [21]. Farm owners select elite cows to be used as donors based on their BCS, but this is the only factor they use when selecting donors. In farms, commercial concentrates and hay are the basic feeds used for Hanwoo cows, and there is no NR guideline for multiple superovulations or embryo recovery. Therefore, we examined the estrus cycle, blood metabolites, $\mathrm{BCS}$, and embryo recovery rate after multiple superovulations and $\mathrm{AI}$ based on different NR.

\section{MATERIALS AND METHODS}

\section{Animals, experimental period, and feed management}

Nineteen Hanwoo cows (mean age $=32.3 \pm 6.9$ months, mean body weight $=436.7 \pm 38.3 \mathrm{~kg}$ ) 
were from the Hanwoo Research Institute, National Institute of Animal Science, Rural Development Administration, Korea, were used in the study. Animal study design were approved by the Institutional Animal Care and Use Committee of the National Institute of Animal Science, Korea (Approval number: NIAS 20191557). The cows were randomly divided into three groups: 80\%, $100 \%$, and $120 \%$ NR groups (containing 6, 8, and 5 cows, respectively). The mean body weight was described as shown follow: $80 \%$ NR group $=455.0 \pm 28.3 \mathrm{~kg}, 100 \%$ NR group $=417.8 \pm 26.9$ $\mathrm{kg}, 120 \% \mathrm{NR}$ group $=437.4 \pm 52.3 \mathrm{~kg}$. All the cows were raised in a pen using a group feeding procedure based on the Korean feeding standard for Hanwoo cows. Commercial formulated concentrates and hay (straw rice) were fed to Hanwoo cows according to the experimental design from December 26, 2018 to April 29, 2019. The 100\% NR group (control) was fed $2.0 \mathrm{~kg}$ of formulated concentrate and $4.0 \mathrm{~kg}$ of hay per cow. The $80 \%$ NR group was fed $1.5 \mathrm{~kg}$ of formulated concentrate and $2.4 \mathrm{~kg}$ of hay per cow. The $120 \%$ NR group was fed $3.0 \mathrm{~kg}$ of formulated concentrate and $5.0 \mathrm{~kg}$ of hay per cow. The chemical compositions of the concentrates and hay are provided in Table 1.

\section{Heat detection and examination of the estrus cycle in Hanwoo cows}

Heat detection was conducted every morning and afternoon for $30 \mathrm{~min}$ from February 21, 2019 to April 29, 2019. To define heat estrus, estrus detection patches (Estrotect ${ }^{\mathrm{TM}}$, Rockway, Spring Valley, WI, USA) were applied about mid-way between the hip and tail head as previously described [22]. To determine the estrus cycle in Hanwoo cows, the follicular wave, ovulation, and corpus luteum formation were examined twice each week (Monday and Thursday) by ultrasonography with 7.5 $\mathrm{MHz}$ probe (NL/MyLab, Esaote, Genova, Italy).

\section{Collection of blood and examination of blood metabolites}

Blood collection was conducted after $2 \mathrm{~h}$ of feeding twice each week (Monday and Thursday) in the morning from February 21, 2019 to April 29, 2019. Ten milliliter of blood samples was collected from the veins of cows using a serum vacutainer (BD vacutainer serum REF 367820, Plymouth, UK) and transferred to the laboratory. Serum was collected by centrifuging the blood sample at $1,763 \times \mathrm{g}$ at $4^{\circ} \mathrm{C}$ for $15 \mathrm{~min}$. The collected serum was cryopreserved in a deep freezer until analysis. We evaluated the following blood metabolites using a blood metabolite analyzer (7020 Automatic Analyzer, Hitachi, Tokyo, Japan): glucose ( $\mathrm{mg} / \mathrm{dL})$, total cholesterol ( $\mathrm{mg} / \mathrm{dL})$, triglyceride $(\mathrm{mg} / \mathrm{dL})$, blood urea nitrogen (BUN, mg/dL), AST (IU/L), ALT (IU/L), NEFA (YEq/L), albumin (ALB, $\mathrm{g} / \mathrm{dL}$ ), and total protein (TP, $\mathrm{g} / \mathrm{dL}$ ).

\section{Superovulation, Al, and embryo recovery}

Nineteen Hanwoo cows with a synchronized estrus cycle were inseminated, and their embryo was recovered between May 7, 2019 and August 1, 2019. Briefly, $1.9 \mathrm{~g}$ of a progesterone-releasing intra-

Table 1. Chemical composition of formulae concentrates and hay (rice straw) to donor cows

\begin{tabular}{lcc}
\hline \multicolumn{1}{c}{ Components } & Concentrates $(\%)$ & Hay $(\%)$ \\
\hline Crude protein & 13.5 & 2.7 \\
Ether extract & 1.5 & 1.98 \\
Ca & 0.7 & 0.13 \\
$\mathrm{P}$ & 0.7 & 0.05 \\
Crude fiber & 15.0 & 34.57 \\
Crude ash & 10.0 & 11.46 \\
TDN & 69.0 & 53.37 \\
\hline
\end{tabular}

TDN, total digestible nutrients. 
vaginal device (EAZI-BREED CIDR 1900, Zoetis, Belgium) was introduced to the vagina of the cows for 7 days, irrespective of the point in the estrus cycle. Four days after CIDR introduction, 28 AU of follicle-stimulating hormones (FSH, Antrin, Japan) was administrated in decreasing dosages twice per day for 4 days (5, 4, 3, and 2 FSH per administration on days 1 to 4, respectively, at 7:30 $\mathrm{AM}$ and 5:30 PM). Six days after CIDR introduction, $25 \mathrm{mg}$ of prostaglandin analog (dinoprost tromethamine; Lutalyse, Zoetis, Belgium) was injected intramuscularly in the morning, and then CIDR was removed. Two days after CIDR withdrawal, AI was accompanied by intramuscular injection of $2 \mathrm{~mL}$ of gonadotrophin-releasing hormone (Fertagyl, Inervet International $\mathrm{GmbH}$, Unterschleissheim, Germany). A second AI was carried out after 2.5 days of CIDR withdrawal. AI was conducted by two well-trained technicians. Freeze-thawed semen from one bull was used for AI. After 7 days of the first AI, embryos were recovered nonsurgically into embryo recovery fluid (Agtech, Manhattan, KS, USA). The recovery fluid was filtered with an embryo collection filter (Agtech), and the embryos were recovered under a stereoscopic microscope. The embryos were classified according to the Manual of International Embryo Transfer Society [23]. As shown Fig. 1 , the recovered embryos from the morulae to expanded blastocyst stages were evaluated, and those
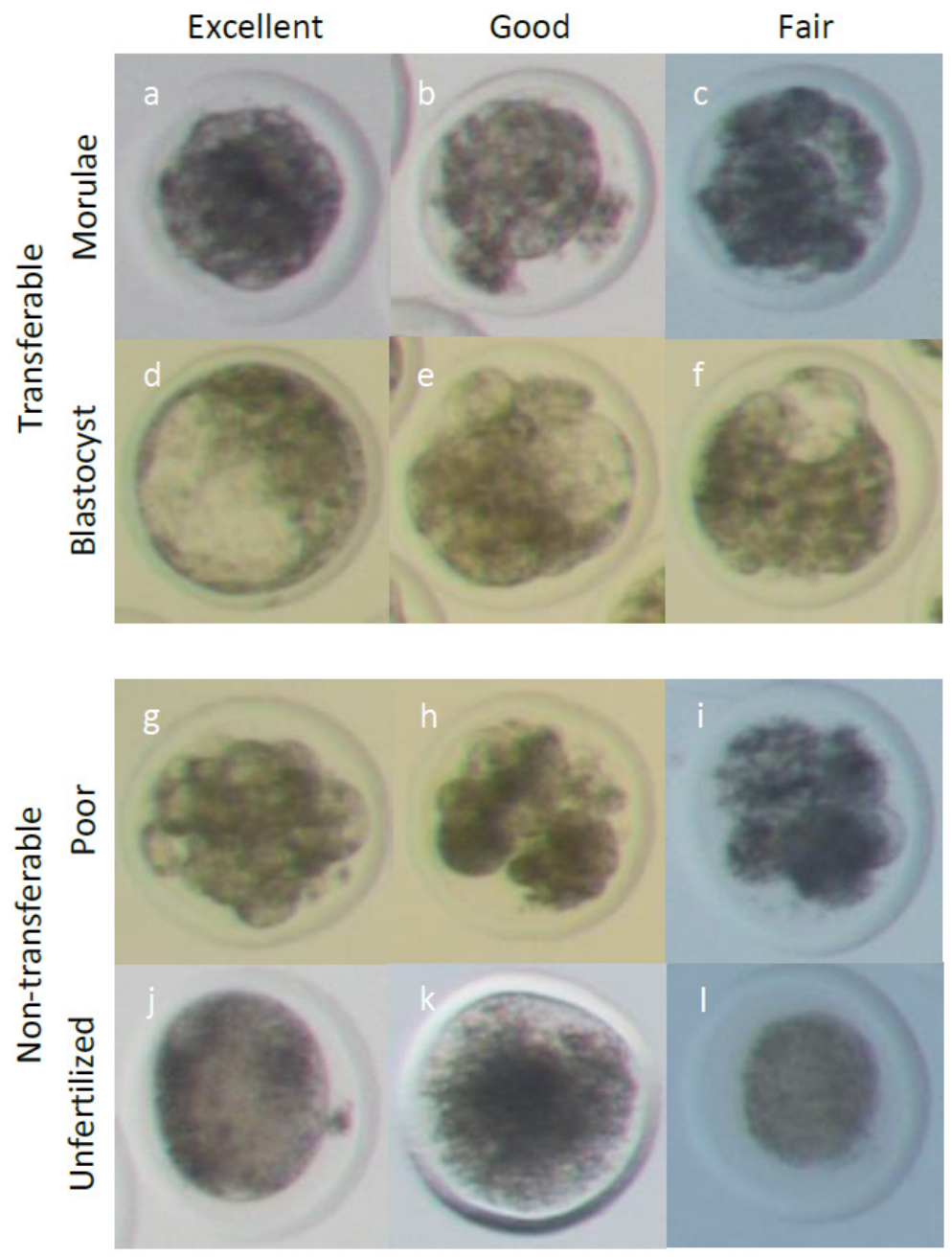

Fig. 1. Embryo morphology under a stereomicroscope by $\times 100$ magnification. The figure shows representative images of recovered embryos from donor cows after multiple superovulation with Al at day 7 . (a-c) morulae, (d-f) blastocyst, ( $\mathrm{g}-\mathrm{i})$ poor embryo, $(\mathrm{j}-\mathrm{l})$; unfertilized oocyte. 
classified as excellent, good (code1), or fair (code2) quality were considered transferable embryos. Unfertilized oocytes and poor-quality embryos were considered as non-transferable embryos.

\section{Statistical analysis}

The blood metabolite levels and body weight among the different NR groups were compared using the one-way ANOVA, followed by Tukey-Kramer's HSD post hoc test. All analyses were performed using SAS (Statistical Analysis System software, version 9.4). The number of transferable embryos among the NR groups was analyzed using the two-tailed Fisher's exact test.

\section{RESULTS}

In the present study, we evaluated blood metabolites and the embryo recovery rate after multiple superovulation and AI in the different NR groups. As shown in Table 2, blood metabolites were changed by different NR. The glucose and ALB levels were not significantly different among the $80 \%, 100 \%$, and $120 \%$ NR groups. Total cholesterol level among the $80 \%, 100 \%$, and $120 \%$ NR groups was significantly different $(126.5 \pm 3.3,152.6 \pm 2.4$, and $177.4 \pm 1.8 \mathrm{mg} / \mathrm{dL} ; p<0.05)$. The level of ALT among the $80 \%, 100 \%$, and $120 \%$ NR groups was significantly different $(21.6 \pm 0.4$, $27.2 \pm 0.5$, and $30.6 \pm 0.5 \mathrm{IU} / \mathrm{L} 4 \mathrm{Eq} / \mathrm{L}$, respectively; $p<0.05$ ). The triglyceride and BUN levels in the $120 \%$ NR group were significantly higher than that of the $80 \%$ and $100 \%$ NR groups $(p<0.05)$. The level of NEFA among the $80 \%, 100 \%$, and $120 \%$ NR groups was significantly different (440.5 $\pm 18.2,318.5 \pm 23.1$, and $195.1 \pm 8.5 \mathrm{GEq} / \mathrm{L}$, respectively; $p<0.05$ ). The levels of AST and TP in the $80 \%$ NR group were significantly low compared that in the $100 \%$ and $120 \%$ NR groups.

The embryo recovery rate from cows in the different NR groups is shown in Table 3. The $120 \%$ NR group presented a significantly high percentage of transferable embryos compared with the $80 \%$ and $100 \%$ NR groups $(55.9 \%, 50.0 \%$, and $90.6 \%$ in the $80 \%, 100 \%$, and $120 \%$ NR groups, respectively; $p<0.01$ ). The body weight, $\mathrm{BCS}$, and estrus cycle duration among the different NR

Table 2. Analysis of Hanwoo cow blood metabolites on different NR levels

\begin{tabular}{|c|c|c|c|}
\hline NR group (\%) & 80 & 100 & 120 \\
\hline $\begin{array}{l}\text { No. cow } \\
\text { (Replicates of each cow) }\end{array}$ & $\begin{array}{c}6 \\
(18)\end{array}$ & $\begin{array}{c}8 \\
(18)\end{array}$ & $\begin{array}{c}5 \\
(18)\end{array}$ \\
\hline Glucose (mg/dL) & $74.1 \pm 5.5$ & $73.8 \pm 5.8$ & $61.6 \pm 5.2$ \\
\hline Total cholesterol (mg/dL) & $126.5 \pm 3.3^{c}$ & $152.6 \pm 2.4^{\mathrm{b}}$ & $177.4 \pm 1.8^{\mathrm{a}}$ \\
\hline Triglyceride (mg/dL) & $24.1 \pm 1.2^{b}$ & $26.5 \pm 1.3^{b}$ & $34.8 \pm 1.2^{\mathrm{a}}$ \\
\hline BUN (mg/dL) & $9.5 \pm 0.5^{b}$ & $9.7 \pm 0.4^{b}$ & $11.6 \pm 0.3^{\mathrm{a}}$ \\
\hline AST (IU/L) & $69.0 \pm 2.1^{\mathrm{b}}$ & $79.8 \pm 2.0^{\mathrm{a}}$ & $75.7 \pm 2.4^{\mathrm{a}}$ \\
\hline ALT (IU/L) & $21.6 \pm 0.4^{c}$ & $27.2 \pm 0.5^{\mathrm{b}}$ & $30.6 \pm 0.5^{\mathrm{a}}$ \\
\hline $\operatorname{NEFA}($ YEq/L) & $440.5 \pm 18.2^{\mathrm{a}}$ & $318.5 \pm 23.1^{\mathrm{b}}$ & $195.1 \pm 8.5^{c}$ \\
\hline ALB (g/dL) & $3.5 \pm 0.2$ & $3.4 \pm 0.2$ & $3.5 \pm 0.3$ \\
\hline $\mathrm{TP}(\mathrm{g} / \mathrm{dL})$ & $7.4 \pm 0.1^{b}$ & $8.2 \pm 0.1^{a}$ & $8.3 \pm 0.1^{\mathrm{a}}$ \\
\hline
\end{tabular}

Blood collection was conducted after $2 \mathrm{~h}$ of feeding in the morning

Blood was collected 18 times per cow, then blood metabolites were analyzed.

All values are mean \pm standard error.

${ }^{a-q}$ Values with different superscripts within a row $(p<0.05)$.

NR, nutrient requirements; BUN, blood urea nitrogen; AST, aspartate aminotransferase; ALT, alanine aminotransferase; NEFA, non-esterified fatty acids; ALB, albumin; TP, total protein. 
Table 3. Embryo recovery rate and embryo classification of different NR groups

\begin{tabular}{lccc}
\hline \multirow{2}{*}{ Parameter } & \multicolumn{3}{c}{ NR (\%) } \\
\cline { 2 - 4 } & $\mathbf{8 0}$ & $\mathbf{1 0 0}$ & $\mathbf{1 2 0}$ \\
\hline Number of cows & 6 & 8 & 5 \\
Total number of recovered embryos & $34(5.7 \pm 2.9)$ & $70(8.7 \pm 4.8)$ & $32(6.4 \pm 2.4)$ \\
Number of excellent & $13(2.2 \pm 1.7)$ & $23(2.9 \pm 2.0)$ & $24(4.8 \pm 1.9)$ \\
Number of good & $6(1.0 \pm 0.6)$ & $12(1.5 \pm 1.5)$ & $5(1.0 \pm 0.7)$ \\
Number of fair & 0 & $2(0.3 \pm 0.5)$ & 0 \\
Number of others & $15(2.5 \pm 2.0)$ & $33(4.1 \pm 2.8)$ & $3(0.6 \pm 0.6)$ \\
Total number of transferable embryos & $19(3.2 \pm 2.0)$ & $37(4.4 \pm 2.9)$ & $29(5.8 \pm 1.9)$ \\
Transferable embryos / recovered embryos $(\%)$ & $55.9^{\mathrm{b}}$ & $50.0^{\mathrm{b}}$ & $90.6^{\mathrm{a}}$ \\
\hline
\end{tabular}

All values are mean \pm standard deviation.

${ }^{a-q}$ Values with different superscripts within a row $(p<0.01)$.

Recovered embryos were evaluated and divided into transferable and non-transferable embryo groups. Transferable embryo group selected from morulae to expanded blastocyst and divided into code 1 (excellent and good) and code 2 (fair). Non-transferable embryo group include the others; unfertilized oocytes, degenerated embryos, poor quality embryos having blastomeres of less than 16.

$\mathrm{NR}$, nutrient requirements.

groups are shown in Table 4. The mean body weight of the 80\%, 100\%, and 120\% NR groups was significantly different $(80 \%, 100 \%$, and $120 \%$ vs. $364.6 \pm 10.0,431.0 \pm 17.6$ and $482.4 \pm 20.3 \mathrm{~kg}$, respectively, $p<0.05$ ). The mean BCS among the $80 \%, 100 \%$, and $120 \%$ NR groups was significantly different $(p<0.05)$. The mean estrus cycle duration among the $80 \%, 100 \%$, and $120 \%$ NR groups was not significantly different. However, the $80 \% \mathrm{NR}$ group showed extended estrus cycle $(24.6 \pm 2.8$ days) compared with the $100 \%$ and $120 \%$ NR groups ( $20.8 \pm 0.2$ and $21.2 \pm 0.5$ days).

\section{DISCUSSION}

In the present study, we showed that different NR affects blood metabolites, number of transferable embryos after multiple superovulation with AI, BCS, and cow estrus cycle in Hanwoo cows. To the best of our knowledge, this study is the first to determine the productivity of transferable embryos from Hanwoo cows by different NR ratio. It has been demonstrated that the nutritional status of donor cow influences oocyte quality, embryo quality, and transferable embryo productivity in vivo [24]. Previous studies reported that feeding beef heifers a high-energy diet resulted in a low number of transferable in vivo embryos after multiple superovulation with $\mathrm{AI}$ [25] and a low number of in vitro embryos derived from the ovum pick up method in Gir cows [26]. In addition, the number of recovered embryos in the $180 \%$ maintenance energy or ad libitum of high-feed intake group after superovulations with $\mathrm{AI}$ was lower than that in the $70 \%$ or $100 \%$ maintenance energy of lowfeed intake groups $[27,28]$. In the present study, we compared small differences in feed-intake level

Table 4. BCS and estrus cycle of Hanwoo cows with different NR levels

\begin{tabular}{|c|c|c|c|c|}
\hline NR (\%) & No. cow & Body weight (kg) & BCS & Estrus cycle (day) \\
\hline 80 & 6 & $364.6 \pm 10.0^{c}$ & $2.6 \pm 0.1^{c}$ & $24.6 \pm 2.8$ \\
\hline 100 & 8 & $431.0 \pm 17.6^{b}$ & $3.2 \pm 0.1^{b}$ & $20.8 \pm 0.2$ \\
\hline 120 & 5 & $482.4 \pm 20.3^{\mathrm{a}}$ & $3.7 \pm 0.1^{\mathrm{a}}$ & $21.2 \pm 0.5$ \\
\hline
\end{tabular}

All values are mean \pm standard error.

a-c Values with different superscripts within a column $(p<0.05)$

BCS, body condition score; NR, nutrient requirements. 
among 80,100 , and $120 \%$ NR groups. The $120 \%$ NR of feed intake group produced a higher number of transferable embryos compared with the $80 \%$ and $100 \%$ NR of feed intake group, as shown in Table 3. The $120 \%$ NR of feed intake was low feed intake level compared with previous studies. Previous studies examined the effect of large differences in the feed-intake level on transferable embryos after superovulation with AI. In a previous study, group fed approximately $3 \mathrm{~kg}$ of concentrate and that fed ad libitum produced 4.8 and 2.8 transferable embryos, respectively $(p<0.05)$ [25]. Approximately $70 \%$ of maintenance energy of the low-feed intake and $180 \%$ of high-feed intake group showed differences in the number of recovered embryos $(10.5$ vs. $6.7, p=0.01)$ and transferable embryos (5.7 vs. 3.8, $p=0.17$ ) [27]. The $100 \%$ and $180 \%$ maintenance feeding groups showed differences in the total number of embryos (14.1 vs. $9.5, p<0.05)$ and number of viable embryos (10.1 vs. 6.7, $p<0.05$ ) [28]. The $70 \%$ and $170 \%$ maintenance feeding groups showed differences in the number of viable (5.3 vs. 3.8, $p=0.028$ ) and total number of embryos ( 9.9 vs. $6.7, p=0.001$ ) [29]. Previous studies demonstrated that low-diet feeding to cows is suitable for producing high quality and transferable embryos. We assumed that excessive feeding of cows might have increased the blood glucose level, which may disturb glucose transportation to the embryos and subsequently decrease the production of high quality embryos [24]. In addition, high-energy diet feeding can increase urea concentration in the blood and rumen, and this is associated with a low pregnancy rate in cows [25]. The results of a study comparing the embryo developmental rate between beef heifers fed high- and low-energy diets showed that the low-energy diet fed cows had a similar embryo quality to that observed in the present study. In beef heifers, the 125\% NRC feeding level resulted in a higher embryo quality and more live cells in the embryo compared with the 80\% NRC feeding level [2].

The effects of different NR on blood metabolites in Hanwoo cows are shown Table 2. The glucose and albumin levels were similar among the $80 \%, 100 \%$, and $120 \%$ NR groups. We could not elucidate the effects of glucose and albumin levels on the embryo recovery rate after multiple superovulations with AI, but we proved that glucose level affects embryonic development in vitro. A high glucose concentration in the embryo culture media deleteriously affected the blastocyst developmental rate compared with a low glucose concentration in bovine [30] and mouse [31]. Bovine serum albumin contains numerous amino acids, and the addition of albumin to a culture medium has a positive effect on embryonic development in vitro [32]. Here, the triglyceride level in the $120 \%$ NR group was significantly higher than that in the $80 \%$ and $100 \%$ NR groups (Table 2). The optimal ranges of triglyceride level, embryo quality, and embryo recovery rate were not directly investigated in cows. There was no difference in the number of transferrable embryos between the non-lactating and lactating cows [33]. The triglyceride level in the blood was higher in non-lactating Holstein cows $(23.8 \pm 0.9 \mathrm{mg} / \mathrm{dL})$ than in lactating cows $(17.2 \pm 0.6 \mathrm{mg} / \mathrm{dL})$. In the present study, cows in the $120 \%$ NR group had a high triglyceride level $(34.8 \pm 1.2 \mathrm{mg} / \mathrm{dL})$ and produced a large number of transferable embryos. Therefore, we conclude that cows with a high triglyceride level in the blood can produce large number of transferable embryos after multiple superovulations with AI. In addition, triglycerides act as an energy source for bovine oocyte maturation in vitro. It has been suggested that the triglyceride levels are lower in mature oocytes than in immature ones [34].

In the present study, a high BUN level in the $120 \% \mathrm{NR}$ group $(11.6 \pm 0.3 \mathrm{mg} / \mathrm{dL})$ resulted in a large number of transferrable embryos compared low BUN levels in the $80 \%$ and $100 \%$ NR groups $(9.5 \pm 0.5$ and $9.7 \pm 0.4 \mathrm{mg} / \mathrm{dL})$. In our previous study, the $120 \% \mathrm{NR}$ group showed higher total cholesterol and BUN levels than the $80 \%$ NR group [35]. This result suggested that $120 \% \mathrm{NR}$ of feed intake increase the total cholesterol and BUN levels in the blood compared with $80 \% \mathrm{NR}$ of feed intake. We assumed that $120 \%$ NR of feed intake induced high production of proteins in liver 
and releasing of BUN compared with $80 \% \mathrm{NR}$ group. The findings of a previous study support our result that high BUN levels $(11-18 \mathrm{mg} / \mathrm{dL})$ resulted in a higher number of transferable embryos $(5.4 \pm 1.9$ embryos) than low BUN levels $(<10 \mathrm{mg} / \mathrm{dL})(3.2 \pm 1.2 \mathrm{embryos})$ [36]. Thus, we believe that the $120 \%$ NR group cows secrete appropriate BUN levels for producing transferable embryos after multiple superovulations with AI. The NEFA level has been used as a predictor of NEB and fertility in cows. In the present study, the low NEFA level $(195.1 \pm 8.5 \mathrm{\varphi Eq} / \mathrm{L})$ in the $120 \% \mathrm{NR}$ group resulted in a higher number of transferrable embryos than the high NEFA levels in the $80 \%$ and $100 \%$ groups (318.5 \pm 23.1 and $440.5 \pm 18 \mathrm{UEq} / \mathrm{L}$, respectively). Dairy cows with high levels of NEFA in the blood had lower fertility than those with low levels of NEFA [37]. In Hanwoo cattle, the pregnant cow group showed significantly lower NEFA levels in the blood than the non-pregnant cow group after $\mathrm{AI}$ (326.7 and 419.2 $\mathrm{YEq} / \mathrm{L}$ in pregnant and non-pregnant cows, respectively; $p<0.05)$ [35]. Cell number and embryo quality decreased when oocytes were exposed to high levels of NEFA in vitro [38]. The AST and ALT levels have been used as an indicator of ketosis by oxidative stress and hepatic damage in dairy cows. However, the effects of normal AST and ALT levels in the donor cow on embryo recovery after multiple superovulations have not been clearly determined. In a previous study, cows with ketosis (hepatic damage) had higher AST and ALT levels than healthy cows (hepatic damage and healthy groups: 160.0 and 85.0 AST (U/L), 35.8 and 22.0 ALT (UL), respectively; $p<0.0001$ ) [39]. In another study, the AST and ALT levels of healthy dairy cows was 43.0 and 37.0 UL, respectively [40]. The AST and ALT levels in the present study were lower than those reported [40]. Hence, different NR in Hanwoo cows did not affect hepatic conditions at any of the NR levels, irrespective of the AST and ALT levels.

In contrast to our result, a previous study showed that Holstein heifers with $2.75 \mathrm{BCS}$ produced more excellent grade embryos than those with 3.0-3.25 BCS [41]. Zebu cattle with a mean BCS of 2.5-3.0 produced more transferable embryos (2.0 embryos) than those with a mean BCS of 4.0-4.5 (0.0) after multiple superovulations with AI [42]. In the present study, cows with a mean BCS of 3.7 produced more transferrable embryos than those with a BCS of 2.6 or 3.2 (Table 4). We believe that the feeding system and circumference affect the number of transferable embryos depending on the cow species. There was no significant difference in the estrus cycle between the $80 \%, 100 \%$, and $120 \%$ NR groups (Table 4). However, the estrus cycle in the $80 \%$ NR group was marginally longer (24.6 \pm 2.8 days) than that in the $100 \%$ and $120 \%$ NR groups ( $20.8 \pm 0.2$ and $21.2 \pm 0.5$ days, respectively). This indicates the cows in the $80 \%$ NR group have a higher NEB. We postulated that the NEB in the $80 \%$ NR group can be elucidated using the highest NEFA level, unlike that in the $100 \%$ and $120 \%$ NR groups. Therefore, the NEB status in the $80 \%$ NR group might have extend the estrus cycles [43].

Our study provides the appropriate feeding level for Hanwoo cows for embryo recovery with multiple superovulations and AI. Blood metabolic tests revealed that Hanwoo cows with 120\% NR had maintained the NEB and produced more transferable embryos. We suggest that $120 \%$ NR and BCS 3.7 are suitable for embryo recovery after multiple superovulations with AI. Therefore, $120 \%$ NR is recommended to produce a large number of transferable, high-quality embryos in Hanwoo cows by multiple superovulations with AI when fed a commercial concentrate and hay (rice straw).

\section{REFERENCES}

1. Villagodoy A, Hughes TL, Emery RS, Stanisiewski EP, Fogwell RL. Influence of energy-balance and body condition on estrus and estrous cycles in Holstein heifers. J Dairy Sci. 1990;73:2759-65.

2. Kruse SG, Bridges GA, Funnell BJ, Bird SL, Lake SL, Arias RP, et al. Influence of post-insem- 
ination nutrition on embryonic development in beef heifers. Theriogenology. 2017;90:185-90.

3. Butler WR. Energy balance relationships with follicular development, ovulation and fertility in postpartum dairy cows. Livest Prod Sci. 2003;83:211-8.

4. Edmonson AJ, Lean IJ, Weaver LD, Farver T, Webster G. A body condition scoring chart for Holstein dairy-cows. J Dairy Sci. 1989;72:68-78.

5. Montiel F, Ahuja C. Body condition and suckling as factors influencing the duration of postpartum anestrus in cattle: a review. Anim Reprod Sci. 2005;85:1-26.

6. Makarevich AV, Stádník L, Kubovičová E, Hegedüšová Z, Holásek R, Louda F, et al. Quality of preimplantation embryos recovered in vivo from dairy cows in relation to their body condition. Zygote. 2016;24:378-88.

7. Garnsworthy PC, Lock A, Mann GE, Sinclair KD, Webb R. Nutrition, metabolism, and fertility in dairy cows: 1. dietary energy source and ovarian function. J Dairy Sci. 2008;91:3814-23.

8. Cozzi G, Ravarotto L, Gottardo F, Stefani AL, Contiero B, Moro L, et al. Reference values for blood parameters in Holstein dairy cows: effects of parity, stage of lactation, and season of production. J Dairy Sci. 2011;94:3895-901.

9. Cetica P, Pintos L, Dalvit G, Beconi M. Activity of key enzymes involved in glucose and triglyceride catabolism during bovine oocyte maturation in vitro. Reproduction. 2002;124:675-81.

10. Leroy JL, Vanholder T, Opsomer G, Van Soom A, de Kruif A. The in vitro development of bovine oocytes after maturation in glucose and $\beta$-hydroxybutyrate concentrations associated with negative energy balance in dairy cows. Reprod Domest Anim. 2006;41:119-23.

11. Rabiee AR, Lean IJ, Gooden JM, Miller BG. Relationships among metabolites influencing ovarian function in the dairy cow. J Dairy Sci. 1999;82:39-44.

12. González FD, Muiño R, Pereira V, Campos R, Benedito JL. Relationship among blood indicators of lipomobilization and hepatic function during early lactation in high-yielding dairy cows. J Vet Sci. 2011;12:251-5.

13. Bobe G, Young JW, Beitz DC. Pathology, etiology, prevention, and treatment of fatty liver in dairy cows. J Dairy Sci. 2004;87:3105-24.

14. Rhoads ML, Rhoads RP, Gilbert RO, Toole R, Butler WR. Detrimental effects of high plasma urea nitrogen levels on viability of embryos from lactating dairy cows. Anim Reprod Sci. 2006;91:1-10.

15. Santos P, Marques A, Antunes G, Chaveiro A, Andrade M, Borba A, et al. Effects of plasma urea nitrogen levels on the bovine oocyte ability to develop after in vitro fertilization. Reprod Domest Anim. 2009;44:783-7.

16. Smuts MP, de Bruyn S, Thompson PN, Holm DE. Serum albumin concentration of donor cows as an indicator of developmental competence of oocytes. Theriogenology. 2019;125:18492.

17. Chapinal N, Carson ME, LeBlanc SJ, Leslie KE, Godden S, Capel M, et al. The association of serum metabolites in the transition period with milk production and early-lactation reproductive performance. J Dairy Sci. 2012;95:1301-9.

18. Lomander H, Gustafsson H, Svensson C, Ingvartsen KL, Frössling J. Test accuracy of metabolic indicators in predicting decreased fertility in dairy cows. J Dairy Sci. 2012;95:7086-96.

19. Jorritsma R, César ML, Hermans JT, Kruitwagen CLJJ, Vos PLAM, Kruip TAM. Effects of non-esterified fatty acids on bovine granulosa cells and developmental potential of oocytes in vitro. Anim Reprod Sci. 2004;81:225-35.

20. Mu YM, Yanase T, Nishi Y, Tanaka A, Saito M, Jin CH, et al. Saturated FFAs, palmitic acid and stearic acid, induce apoptosis in human granulosa cells. Endocrinology. 2001;142:3590-7.

21. Callesen H, Liboriussen T, Greve T. Practical aspects of multiple ovulation embryo transfer in 
cattle. Anim Reprod Sci. 1996;42:215-26.

22. Colazo MG, Whittaker P, Macmillan K, Bignell D, Boender G, de Carvalho Guimaraes R, et al. Evaluation of a modified GnRH-based timed-AI protocol associated with estrus detection in beef heifers inseminated with sex-selected or conventional semen. Theriogenology. 2018;118:90-5.

23. Stringfellow DA, Seidel SM. Manual of the international embryo transfer society: a procedural guide and general information for the use of embryo transfer technology, emphasizing sanitary precautions. 3rd ed. Savoy, Il: International Embryo Transfer Society; 1998.

24. Santos JEP, Ceri RLA, Sartori R. Nutritional management of the donor cow. Theriogenology. 2008;69:88-97.

25. Yaakub H, O'Callaghan D, Boland MP. Effect of type and quantity of concentrates on superovulation and embryo yield in beef heifers. Theriogenology. 1999;51:1259-66.

26. Sales JNS, Iguma LT, Batista RITP, Quintão CCR, Gama MAS, Freitas C. Effects of a high-energy diet on oocyte quality and in vitro embryo production in Bos indicus and Bos taurus cows. J Dairy Sci. 2015;98:3086-99.

27. Mollo MR, Rumpf R, Martins AC, Carrijo LHD, Saueressig MG, Sartori R. Embryo production in superovulated Nelore heifers under low or high feed take. Acta Sci Vet. 2007;35:s1241.

28. Bastos MR, Ramos AF, Driessen K, Martins AC, Rumpf R, Sartori R. Effect of nutritional flushing on the superovulatory response of crossbred cows. Acta Sci Vet. 2007;35:s1242.

29. Mollo MR, Monteiro PLJ, Surjus RS, Martins AC, Ramos AF, Mourão GB, et al. Embryo production in heifers with low or high dry matter intake submitted to superovulation. Theriogenology. 2017;92:30-5.

30. Uhde K, van Tol HTA, Stout TAE, Roelen BAJ. Exposure to elevated glucose concentrations alters the metabolomic profile of bovine blastocysts. PLOS ONE. 2018;13:e0199310.

31. Bermejo-Alvarez P, Roberts RM, Rosenfeld CS. Effect of glucose concentration during in vitro culture of mouse embryos on development to blastocyst, success of embryo transfer, and litter sex ratio. Mol Reprod Dev. 2012;79:329-36.

32. Orsi NM, Leese HJ. Amino acid metabolism of preimplantation bovine embryos cultured with bovine serum albumin or polyvinyl alcohol. Theriogenology. 2004;61:561-72.

33. Leroy JLMR, Opsomer G, De Vliegher S, Vanholder T, Goossens L, Geldhof A, et al. Comparison of embryo quality in high-yielding dairy cows, in dairy heifers and in beef cows. Theriogenology. 2005;64:2022-36.

34. Cetica P, Pintos L, Dalvit G, Beconi M. Activity of key enzymes involved in glucose and triglyceride catabolism during bovine oocyte maturation in vitro. Reproduction. 2002;124:675-81.

35. Kang SS, Kim UH, Lee SD, Lee MS, Kwon EK, Jang SS, et al. Basic analysis of metabolic parameters by using metabolic profile test (MPT) for improvement breeding in Korean native cow.J Korean Soc Grassl Forage Sci. 2018;38:331-6.

36. Son JK, Choe CY, Cho SR, Yeon SH, Choi SH, Kim NT, et al. Relationship between superovulation treatment and blood urea nitrogen (BUN) concentration in Hanwoo donors. Reprod Dev Biol. 2010;34:201-5.

37. Wathes DC, Fenwick M, Cheng Z, Bourne N, Llewellyn S, Morris DG. Influence of negative energy balance on cyclicity and fertility in the high producing dairy cow. Theriogenology. 2007;68:S232-41.

38. Van Hoeck V, Sturmey RG, Bermejo-Alvarez P, Rizos D, Gutierrez-Adan A, Leese HJ, et al. Elevated non-esterified fatty acid concentrations during bovine oocyte maturation compromise early embryo physiology. PLOS ONE. 2011;6:e23183.

39. Du X, Chen L, Huang D, Peng Z, Zhao C, Zhang Y, et al. Elevated apoptosis in the liver of 
dairy cows with ketosis. Cell Physiol Biochem. 2017;43:568-78.

40. Kalaitzakis E, Panousis N, Roubies N, Giadinis N, Kaldrymidou E, Georgiadis M, et al. Clinicopathological evaluation of downer dairy cows with fatty liver. Can Vet J. 2010;51:615-22.

41. Kadokawa H, Tameoka N, Uchiza M, Kimura Y, Yonai M. A field study on the relationship between body condition and embryo production in superovulated Holstein yearling heifers. J Dairy Sci. 2008;91:1087-91.

42. Siddiqui MAR, Shamsuddin M, Bhuiyan MMU, Akbar MA, Kamaruddin KM. Effect of feeding and body condition score on multiple ovulation and embryo production in zebu cows. Reprod Domest Anim. 2002;37:37-41.

43. Butler WR, Smith RD. Interrelationships between energy-balance and postpartum reproductive function in dairy-cattle. J Dairy Sci. 1989;72:767-83. 